УДК 543.544:547.913

\title{
ИССЛЕДОВАНИЕ КОНЦЕНТРАЦИОННОЙ ЗАВИСИМОСТИ ЭФФЕКТОВ СИНЕРГИЗМА И АНТАГОНИЗМА В СМЕСЯХ ЭФИРНЫХ МАСЕЛ ЛИМОНА, КОРИАНДРА И ПОЧЕК ГВОЗДИКИ
}

\section{(C) А.Л. Самусенко}

\author{
Институт биохимической фризики им. Н.М.Эмануэля РАН, ул. Косыгина, 4, \\ Москва, 119991 (Россия), e-mail: Samusenko.alexey@rambler.ru
}

Изучение антиоксидантной активности (AOA) эфирных масел пряно-ароматических растений является важной задачей для косметической химии, ароматерапии, пищевой и парфюмерной промышленности. Обычно для разработки рецептур в указанных отраслях используют не индивидуальные масла, а смеси двух или нескольких масел. В этом случае могут проявляться эффекты синергизма и антагонизма. Ранее при изучении смеси масел гвоздики и лимона мы обнаружили эффект синергизма, который выражался в увеличении АОА данной смеси по сравнению с аналогичной величиной для индивидуальных масел, а при исследовании смеси масел лимона и кориандра - антагонизма, приводящего к резкому уменьшению АОА. Однако наши данные по АОА смесей эфирных масел были получены при одной и достаточно высокой концентрации масел в растворе. Цель данной работы - изучить зависимость АОА смесей эфирных масел от их концентрации в системе и оценить концентрационную зависимость эффектов синергизма и антагонизма в смесях масел. Методом капиллярной газо-жидкостной хроматографии исследована зависимость антиоксидантной активности смесей эфирных масел лимона (Citrus limon), кориандра (Coriandrum sativum L.) и почек гвоздики (Caryophyllus aromaticus L.), а также явлений синергизма и антагонизма масел от концентрации их смесей в растворе. Оценка антиоксидантных свойств смесей масел проведена по реакции окисления транс-2-гексеналя в соответствующую карбоновую кислоту. Найдено, что с уменьшением концентрации смесей масел в растворе, несмотря на разнонаправленность эффектов, проявление как синергизма, так и антагонизма становится менее выраженным. Антагонизм масел лимона и кориандра в значительной степени нивелируется добавлением масла гвоздики, обладающим высокой антиоксидантной активностью. Выявлена роль сильных и слабых антиоксидантов, входящих в состав изученных масел, в синергизме и антагонизме их смесей, что дало возможность прояснить механизм этих явлений.

Ключевые слова: эфирные масла пряно-ароматических растений, антиоксидантная активность, синергизм, антагонизм, капиллярная газовая хроматография.

\section{Введение}

В последнее время в результате многочисленных исследований установлена биологическая активность эфирных масел пряно-ароматических растений, в том числе антиоксидантная [1-3]. Поскольку пряно-ароматические растения являются источниками природных антиоксидантов, использование их эфирных масел представляет альтернативу синтетическим антиоксидантам, которые потенциально опасны для здоровья человека [4]. Поэтому изучение антиоксидантной активности (АОА) эфирных масел пряноароматических растений является важной задачей для косметической химии, ароматерапии, пищевой и парфюмерной промышленности.

Обычно для разработки рецептур в указанных отраслях используют не индивидуальные масла, а смеси двух или нескольких масел. В связи с этим необходимо иметь данные по АОА не только самих масел, но также и их смесей. Следует отметить, что в последнем случае могут проявляться эффекты синергизма и антагонизма. Так, например, при изучении смеси масел гвоздики и лимона мы обнаружили эффект синергизма, который выражался в увеличении АОА данной смеси по сравнению с аналогичной величиной для индивидуальных масел, а при исследовании смеси масел лимона и кориандра - антагонизма, приводящего к резкому уменьшению АOA [5]. Необходимость исследования эффектов синергизма и антагонизма

Самусенко Алексей Леонидович - научный сотрудник лаборатории комплексной оценки биоантиоксидантов, тел.: (499) 135-78-94, e-mail: Samusenko.alexey@rambler.ru подробно рассмотрена в монографии [6], там же показана возможность синергизма и антагонизма 
между фенольными соединениями и другими антиоксидантами. Изучен механизм влияния полярности растворителя на синергизм синтетических антиоксидантов [7]. В работе [8] обнаружена концентрационная зависимость эффектов синергизма и антагонизма смеси эфирных масел гвоздики и корицы по отношению к грамотрицательным и грамположительным бактериям.

Наши данные по АОА смесей эфирных масел были получены при одной и достаточно высокой концентрации масел в растворе. Поэтому представляется интересным исследовать зависимость АОА и величин эффектов синергизма и антагонизма от концентрации смеси масел в растворе, тем более что такие сведения в литературе практически отсутствуют.

Цель работы - изучить зависимость АОА смесей эфирных масел лимона, кориандра и гвоздики от их концентрации в системе и оценить концентрационную зависимость эффектов синергизма и антагонизма в указанных смесях масел.

\section{Экспериментальная часть}

Исследовали свежие образцы эфирных масел: лимона (Citrus limon), (R. C. TREATT, Великобритания), кориандра (Coriandrum sativum L.) и почек гвоздики (Caryophyllus aromaticus L.) (Plant Lipids Ltd., Индия).

Для оценки АО свойств эфирных масел в 50 мл н-гексана растворили 400 мкл транс-2-гексеналя и 400 мкл н-додекана (8 мкл/мл); последний служил внутренним стандартом. Раствор разделили на аликвоты по 2 мл, которые поместили в стеклянные пробирки объемом 10 мл, и добавили по 100, 50 или 20 мкл эфирных масел лимона, кориандра и почек гвоздики. Концентрации масла в приготовленных растворах, строго говоря, составляли 4,76, 2,44 и 0,99\%, но для удобства сравнения и построения диаграмм были условно приняты равными $5 ; 2,5$ и $1 \%$ соответственно. Смеси масел: лимона и кориандра; лимона и гвоздики; лимона, кориандра и гвоздики готовили аналогичным образом, сохраняя соотношение концентраций масел в смесях $1: 1$ и $1: 1: 1$. Таким образом получили наборы трех смесей масел с теми же концентрациями каждого из масел в растворе, то есть 5, 2,5 и 1 об.\%. Каждый образец был приготовлен двукратно. Образцы в закрытых пробками пробирках держали на свету при комнатной температуре в течение 120 сут. Источником света служило естественное освещение в лаборатории. Каждую неделю пробирки открывали и продували 10 мл воздуха с помощью пипетки. Количественное содержание гексеналя в пробирках определяли методом капиллярной газовой хроматографии через каждые 8-12 сут. Изменения в составе эфирных масел фиксировали через 1, 2, 3 и 4 мес. с начала хранения.

Газохроматографический анализ образцов эфирных масел проводили на хроматографе Micromat-412 фирмы Nordion Instr. (Финляндия) на кварцевой капиллярной колонке SPB-1 (Supelco, CША, 35 м × 0,32 мм, толщина слоя фазы 0,25 мкм) при программировании температуры колонки от 60 до $250{ }^{\circ} \mathrm{C}$ со скоростью 8 \%мин. Скорость газа-носителя гелия составляла 1 мл/мин, температура инжектора и пламенноионизационного детектора $-250{ }^{\circ} \mathrm{C}$. Идентификацию компонентов в образцах масел осуществляли на основе величин индексов удерживания путем их сопоставления с литературными [9] или экспериментальными данными, полученными нами. Количественное содержание гексеналя и компонентов эфирных масел рассчитывали по отношению площадей пиков, соответствующих веществам и внутреннему стандарту, содержание которого принимали кратным 8 мкл/мл. Степень окисления гексеналя и компонентов эфирных масел (отн.\%) определяли по отношению к их содержанию в исходных образцах.

\section{Результаты и обсуждение}

Для оценки АОА исследуемых эфирных масел мы использовали тест «альдегид/карбоновая кислота» [10]. Тест-вещество и критерий для оценки АОА изучаемых масел выбраны аналогично работе [11].

В качестве оценки эффектов синергизма и антагонизма в смесях эфирных масел следует принять разницу в величинах периода полуокисления (ПО) альдегида в растворах индивидуальных масел и их смесей. Мы проследили изменение величины ПО в зависимости от концентрации смеси в растворе и сравнили их с аналогичными концентрациями индивидуальных масел. На рисунке 1 представлены данные по 5\% концентрации всех изученных смесей. Для выяснения механизма эффектов синергизма и антагонизма провели дополнительный эксперимент на примере $5 \%$ концентрации по определению ПО альдегида в таких же условиях, но смешивали только основные, значимые для АОА, отдельные компоненты масел, а именно: для масла лимона - $\gamma$-терпинен, кориандра - линалоол и гвоздичного - эвгенол. Данные соединения обладают, за ис- 
ключением линалоола, высокой АОА, и их содержание в составе изученных масел составляет 10,5, 73 и 81\% соответственно. Следует особо подчеркнуть, что растворы подбирались так, чтобы концентрации отдельных компонентов точно соответствовали их концентрациям в смесях их содержащих масел.

Как следует из рисунка 1, наблюдали четко выраженный синергизм в смеси лимона и гвоздики. В растворе индивидуальных масел ПО альдегида составлял 60 и 97 сут. для лимона и гвоздики соответственно. В смеси с той же концентрацией исходных масел ПО составлял 107 сут., то есть больше того или другого масла, взятых в отдельности. Это может быть связано с наличием в смеси двух сильных АОсоединений - $\gamma$-терпинена и эвгенола, причем в достаточно высоких концентрациях. При смешении масел лимона и кориандра наблюдали обратный эффект - антагонизма, который выражался в уменьшении величин ПО, то есть 60 и 69 сут. соответственно в масле лимона и кориандра и только 50 сут. в их смеси. Явление антагонизма в смесях эфирных масел с практической точки зрения в пищевой или парфюмерной промышленности, безусловно, является нежелательным, и его механизм практически не изучен [8]. Известно, что AОА любого соединения, то есть ингибирование активных кислородсодержащих частиц, напрямую связано с его способностью самому окисляться и тем самым замедлять радикальную реакцию окисления субстрата. $\gamma$-терпинен, содержащий в кольце 2 двойные связи, быстро окисляется до $p$-цимена:

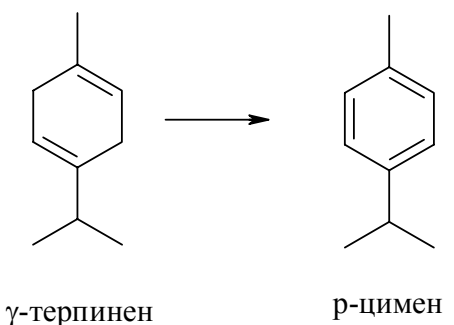

Линалоол окисляется до цุис- и транс-линаоол-оксидов, а в дальнейшем - до цитраля (смесь двух изомеров - гераниаль + нераль):

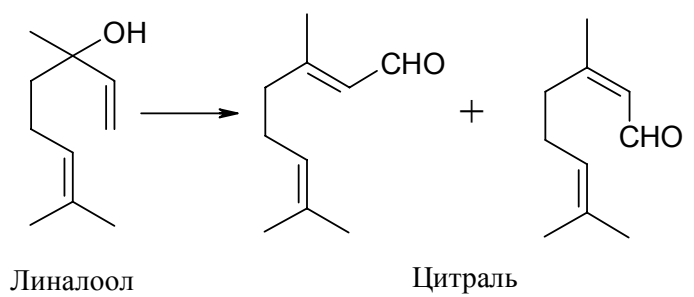

причем этот процесс в масле кориандра, как показано в [5], проходит гораздо медленнее, чем окисление $\gamma$-терпинена в лимонном масле. Тем не менее в данном случае можно полагать, что большое содержание слабого антиоксиданта, а именно линаоола, препятствует быстрому окислению сильного АО-соединения $\gamma$-терпинена, вследствие чего и уменьшается АОА смеси масел лимона и кориандра (см. рис. 1). Обнаружено также [5], что образование р-цимена вследствие окисления $\gamma$-терпинена происходит в 3,5 раза медленнее в смеси масел лимона и кориандра, чем в индивидуальном масле лимона.

Интересно отметить, что для смеси индивидуальных компонентов этих же масел лимона и гвоздики получены аналогичные результаты (рис. 1), что подтверждает их важную роль не только в АОА масел, но и в синергизме и антагонизме, возникающих в смесях масел по отношению к окислению тест-альдегида. Несмотря на то, что принято считать окислительно-восстановительный потенциал всей системы масла выше, чем отдельных ее компонентов, мы не обнаружили существенной разницы в синергизме или антагонизме смесей масел и их основных компонентов. Однако полученного материала недостаточно, чтобы полностью исключить влияние минорных компонентов масел на формирование синергизма или антагонизма.

На рисунках 2 и 3 представлены аналогичные данные по 2,5 и 1\% смесям масел. Наличие трех различных концентраций смесей масел в растворе позволяет проследить концентрационную зависимость величин эффектов синергизма и антагонизма. Как видно из сопоставления рисунков 1-3, с понижением концентрации смеси масел в растворе оба эффекта, как синергизм, так и антагонизм, ослабевают, и при концентрации $1 \%$ они практически нивелируются. Вероятно, это связано с общей тенденцией уменьшения АОА масел при их низких концентрациях, причем наиболее заметно это явление выражено для масла кориандра [12]. 


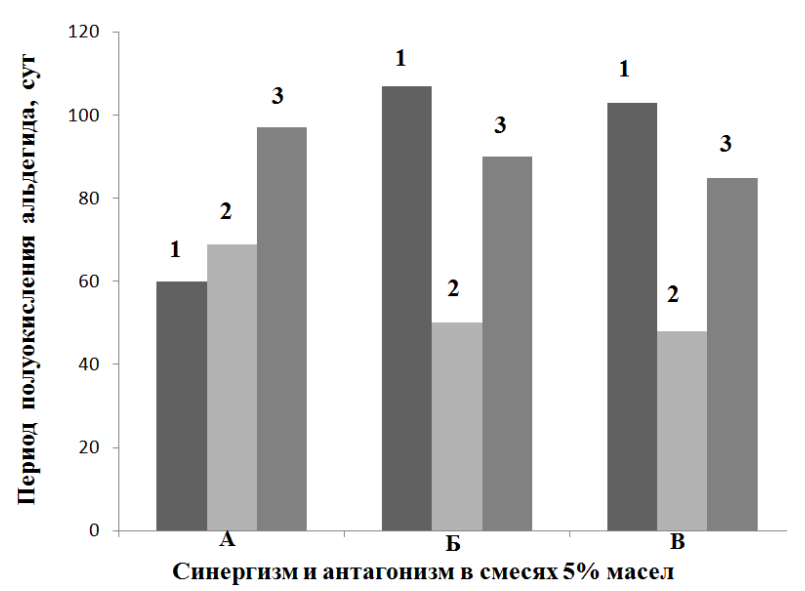

Рис. 1

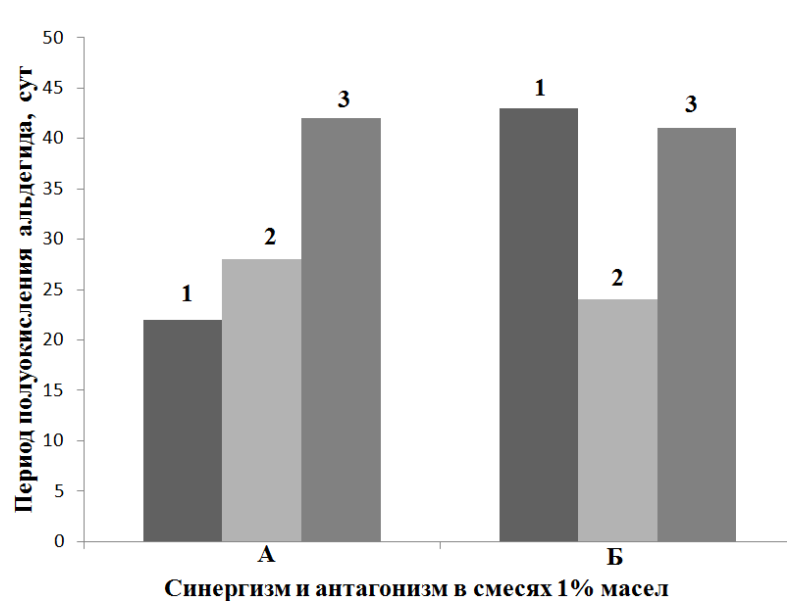

Рис. 3

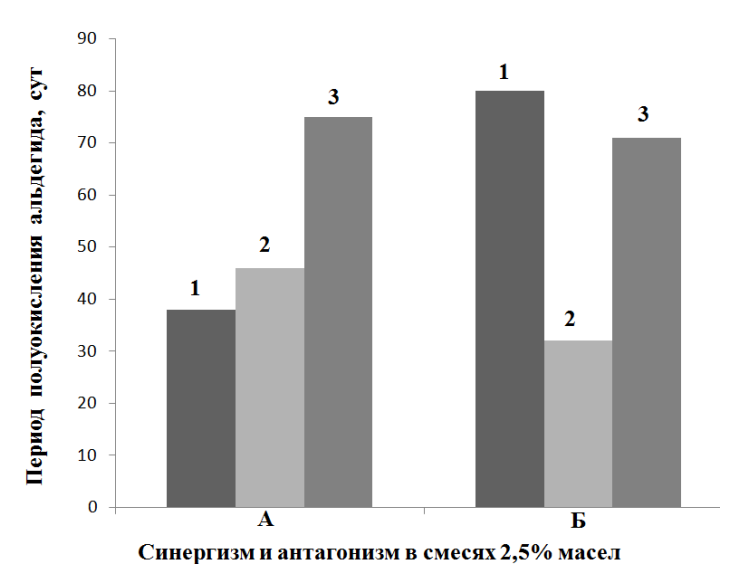

Рис. 2
Зависимость периода полуокисления транс-2гексеналя от концентрации индивидуальных масел лимона, кориандра и гвоздики (А), смесей этих масел (Б) и смесей отдельных компонентов масел (В) в растворе с концентрацией $5 \%$ (рис. 1), 2,5\% (рис. 2), 1\% (рис. 3). А: 1 - лимон, 2 - кориандр, 3 - гвоздика; Б: 1 - лимон + гвоздика, 2 - лимон + кориандр, 3 - лимон + кориандр + гвоздика; В: $1-\gamma$-терпинен + эвгенол, $2-\gamma$-терпинен + линалоол, $3-\gamma$-терпинен + линалоол + эвгенол

В случае тройной смеси масел «лимон + кориандр + гвоздика» мы наблюдали смешанный эффект, то есть антагонизм масел лимона и кориандра в определенной степени подавляется синергизмом масел лимона и гвоздики. Данная смесь проявляет достаточно высокую АОА (рис. 1) и в то же время содержит масла-антагонисты. Аналогичные результаты получены и при смешении выбранных нами отдельных компонентов всех трех масел (рис. 1). Таким образом, если необходимо добавить к лимону кориандр (по каким-либо рецептурным требованиям), то необходимо добавить и гвоздику, чтобы подавить антагонизм первых двух масел и сохранить высокую АОА системы. С практической точки зрения такой подход к составлению многокомпонентных смесей является наиболее оптимальным, так как расширяет возможности смешения различных масел. Можно заметить, что дальнейшие исследования различных многокомпонентных смесей масел могли бы дать более широкий спектр сведений по этому поводу.

\section{Выводы}

Методом капиллярной газо-жидкостной хроматографии показано, что при уменьшении концентрации смесей масел в растворе во всех случаях наблюдали ослабление как синергизма, так и антагонизма, несмотря на разную направленность этих эффектов.

Отмечено, что синергизм в смеси масел лимона и гвоздики обусловлен наличием двух сильных антиоксидантов - $\gamma$-терпинена и эвгенола, а явление антагонизма в смеси масел лимона и кориандра связано с ингибированием окисления сильного антиоксиданта $\gamma$-терпинена большим количеством более слабого линалоола.

В случае сложных смесей масел, где присутствуют синергизм и антагонизм одновременно, желаемая величина АОА достигается подборкой соотношения исходных индивидуальных масел. 
Дальнейшие исследования синергизма и антагонизма более широкого спектра смесей масел позволят целенаправленно регулировать АОА смесей эфирных масел или их компонентов с заранее заданными свойствами.

\section{Список литературы}

1. Hsu F.-L., Li W.-H., Yu C.-W., Hsieh Y.-C., Yang Y.-F., Liu J.-T., Shih J., Chu Y.-J., Yen P.-L., Chang S.-T., Liao V. H.-C. In Vivo Antioxidant Activities of Essential Oils and Their Constituents from Leaves of the Taiwanese Cinnamomum osmophloeum // J. Agric. Food Chem. 2012. Vol. 60, N12. Pp. 3092-3097.

2. Özcan M.M., Arslan D. Antioxidant effect of essential oils of rosemary, clove and cinnamon on hazelnut and poppy oils // Food Chem. 2011. Vol. 129, N1. Pp. 171-174.

3. El-Ghorab H., Nauman M., Anjum F.M., Hussain S., Nadeem M. A Comparative Study on Chemical Composition and Antioxidant Activity of Ginger (Zingiber officinale) and Cumin (Cuminum cyminum) // J. Agric. Food Chem. 2010. Vol. 58, N14. Pp. 8231-8237.

4. Schilderman P., ten Vaarwerk F.J., Lutgerink J.T., Van der Wurff A., ten Hoor F., Kleinjans J.C. Induction of oxidative DNA damage and early lesions in rat gastro-intestinal epithelium in relation to prostaglandin $\mathrm{H}$ synthasemediated metabolism of butylated hydroxyanisole // Food Chem. Toxicol. 1995. Vol. 33. Pp. 99-109.

5. Самусенко А.Л. Исследование антиоксидантной активности эфирных масел лимона, розового грейпфрута, кориандра, гвоздики и их смесей методом капиллярной газовой хроматографии // Химия растительного сырья. 2011. №3. С. 107-112.

6. Меньщикова Е.Б., Ланкин В.З., Кандалинцева Н.В. Фенольные антиоксиданты в биологии и медицине. Строение, свойства, механизмы действия. Lambert AP, 2012. 488 с.

7. Marteau C., Favier D., Nardello-Rataj V., Aubry J.-M. Dramatic solvent effect on the synergy between $\alpha$-tocopherol and BHT antioxidants // Food Chem. 2014. Vol. 160. Pp. 190-195.

8. Goñi P., López P., Sánchez C., Gómez-Lus R., Becerril R., Nerín C. Antimicrobial activity in the vapour phase of a combination of cinnamon and clove essential oils // Food Chem. 2009. Vol. 116, N4. Pp. 982-989.

9. Jennings W., Shibamoto T. Qualitative Analysis of Flavor and Fragrance Volatiles by Glass Capillary Gas Chromatography. New York ; London ; Sydney; Toronto ; San Francisco, 1980. 472 p.

10. Lee K.G., Shibamoto T. Determination of antioxidant potential of volatile extracts isolated from various herbs and species // J. Agric. Food Chem. 2002. Vol. 50, N17. Pp. 4947-4952.

11. Samusenko A.L. Comparative evaluation of antioxidant properties of spice-aromatic plant essential oils // Oxidation Communications. 2008. Vol. 31, N2. Pp. 275-284.

12. Самусенко А.Л. Изучение зависимости антиоксидантной активности эфирных масел кориандра, имбиря, семян тмина и розового грейпфрута от концентрации масла в системе методом капиллярной газовой хроматографии // Химия растительного сырья. 2014. №1. С. 221-227.

Поступило в редакиию 20 октября 20152. 
Samusenko A.L. A STUDY OF THE CONCENTRATION DEPENDENCE OF THE EFFECTS OF SYNERGISM AND ANTAGONISM IN MIXTURES OF ESSENTIAL OILS FROM LEMON, CORIANDER AND CLOVE BUDS

N.M. Emanuel Institute of Biochemical Physics Russian Academy of Sciences, Kosygina st., 4, Moscow, 119991 (Russia), e-mail: Samusenko.alexey@rambler.ru

Study of antioxidant activity (AOA) of essential oils of aromatic plants is an important task for cosmetic chemistry, aromatherapy, food and perfume industry. Usually for creating the compositions in these sectors the researchers use a mixture of two or more oils, rather than the individual ones. In this case, the effects of synergism and antagonism can occur. Previously when studying mixtures of oils from clove and lemon we found a synergistic effect, which was expressed in the increase of AOA of this mixture compared with the corresponding value for the individual oils, and in the study of the mixture of oils from lemon and coriander - antagonism, leading to a sharp decrease in AOA. However, our data on AOA of essential oil mixtures were obtained by one and a sufficiently high concentration of oils in the solution. The aim of this work is to study the dependence of AOA of essential oil mixtures on their concentration in the system and to evaluate the concentration dependence of the synergism and antagonism effects in mixtures of oils. By capillary gas-liquid chromatography dependence of antioxidant activity of mixtures of essential oils from lemon (Citrus limon), coriander (Coriandrum sativum L.) and clove buds (Caryophyllus aromaticus L.), as well as synergism and antagonism oils on the concentration of their mixtures in solution was investigated. Evaluation of antioxidant properties of oil mixtures has been studied using an aldehyde/carboxylic acid assay. Trans-2-hexenal was selected to serve as the test substance. It was found that with decreasing concentration of oil mixtures in the solution, despite the difference in character of these effects, the manifestation of synergism and antagonism became less pronounced. Antagonism oils of lemon and coriander largely offset by the addition of clove oil with high antioxidant activity. The role of strong and weak antioxidants in the oil composition was revealed in synergism and antagonism of their mixtures, which gave the opportunity to clarify the mechanism of these phenomena.

Keywords: essential oils from spicy-aromatic herbs, antioxidant activity, synergism, antagonism, capillary gas chromatography.

\section{References}

1. Hsu F.-L., Li W.-H., Yu C.-W., Hsieh Y.-C., Yang Y.-F., Liu J.-T., Shih J., Chu Y.-J., Yen P.-L., Chang S.-T., Liao V. H.-C. J. Agric. Food Chem., 2012, vol. 60, no. 12, pp. 3092-3097.

2. Özcan M.M., Arslan D. Food Chem., 2011, vol. 129, no. 1, pp. 171-174.

3. El-Ghorab H., Nauman M., Anjum F.M., Hussain S., Nadeem M. J. Agric. Food Chem., 2010, vol. 58, no. 14, pp. 8231-8237.

4. Schilderman P., ten Vaarwerk F.J., Lutgerink J.T., Van der Wurff A., ten Hoor F., Kleinjans J.C. Food Chem. Toxicol., 1995, vol. 33, pp. 99-109.

5. Samusenko A.L. Khimiia rastitel'nogo syr'ia, 2011, no. 3, pp. 107-112. (in Russ.).

6. Men'shchikova E.B., Lankin V.Z., Kandalintseva N.V. Fenol'nye antioksidanty v biologii $i$ meditsine. Stroenie, svoistva, mekhanizmy deistviia. [Phenolic antioxidants in biology and medicine. Structure, properties, mechanisms of action]. Lambert AP, 2012, 488 p. (in Russ.).

7. Marteau C., Favier D., Nardello-Rataj V., Aubry J.-M. Food Chem., 2014, vol. 160, pp. 190-195.

8. Goñi P., López P., Sánchez C., Gómez-Lus R., Becerril R., Nerín C. Food Chem., 2009, vol. 116, no. 4, pp. $982-989$.

9. Jennings W., Shibamoto T. Qualitative Analysis of Flavor and Fragrance Volatiles by Glass Capillary Gas Chromatography. New York ; London ; Sydney ; Toronto ; San Francisco, 1980. 472 p.

10. Lee K.G., Shibamoto T. J. Agric. Food Chem., 2002, vol. 50, no. 17, pp. 4947-4952.

11. Samusenko A.L. Oxidation Communications, 2008, vol. 31, no. 2, pp. 275-284.

12. Samusenko A.L. Khimiia rastitel'nogo syr'ia, 2014, no. 1, pp. 221-227. (in Russ.). 